\title{
As Vilas Olímpicas na cidade do Rio de Janeiro e as chamadas organizações sociais: o neoliberalismo em campo*
}

\author{
Olympic Villages in Rio de Janeiro and so-called social
} organizations: neoliberalism in the field

\author{
Marcelo Paula de Melo** \\ Gustavo Martins de Andrade*** \\ Marina Boechat da Cunha****
}

\begin{abstract}
Resumo - O objetivo deste texto é discutir as políticas municipais de esporte do Rio de Janeiro, a partir da aprovação da Lei das Organizações Sociais (OS) em 2009. Esta viabilizou ao bloco no poder travar relações com organismos na sociedade civil para gerir os equipamentos conhecidos como Vilas Olímpicas. Esse mecanismo de atuação estatal insere-se no bojo das recomendações dos organismos internacionais dominantes para as políticas sociais, sendo uma característica marcante da privatização dessas políticas.

Palavras-chave: Vilas Olímpicas; organizações sociais, Rio de Janeiro; privatização.
\end{abstract}

\begin{abstract}
The goal of this paper is to discuss the city of Rio de Janeiro's sport policies, from the approval of the Law of Social Organizations in 2009. This law enabled the coalition in power to engage with civil society organizations in order to manage the assets known as Olympic Villages. This state action mechanism is part of the social policies recommendations of dominant international organizations, and a hallmark of the privatization of these policies. Keywords: Olympic Villages; social organizations; Rio de Janeiro; privatization.
\end{abstract}

\footnotetext{
* Essa pesquisa contou com bolsa Pibic-Ufrj.

** Doutor em Serviço Social pela Universidade Federal do Rio de Janeiro. Docente na Escola de Educação Física e Desportos da Universidade Federal do Rio de Janeiro (EEFD/UFRJ). Líder do grupo de pesquisa Coletivo de Estudos de Políticas Públicas de Esporte, Educação Física e Lazer- EEFD/UFRJ. Correspondência: Escola de Educação Física e Desportos- UFRJ. Depto de ginástica - sala 221. Av. Carlos Chagas Filho, 540 - Cidade Universitária, Rio de Janeiro -RJ. CEP: 21940-901. Email: <marcelaomelo@gmail.com>.

*** Mestrando em Serviço Social pela Universidade do Estado do Rio de Janeiro (UERJ), licenciado em Educação Física EEFD/UFRJ. Correspondência: Escola de Educação Física e Desportos- UFRJ. Depto de ginástica- sala 221. Av. Carlos Chagas Filho, 540 - Cidade Universitária, Rio de Janeiro - RJ. CEP: 21940-901. Email: <gmartins_157 @hotmail.com>.

**** Aluna da residência multiprofissional em saúde HUAP-UFF, licenciada em Educação Física (EEFD/UFRJ). Correspondência: Escola de Educação Física e Desportos- UFRJ. Depto de ginástica - sala 221. Av. Carlos Chagas Filho, 540 - Cidade Universitária, Rio de Janeiro-RJ. CEP: 21940-901. Email: <marinabc11@hotmail.com>.
} 


\section{Introdução}

Este trabalho investiga os desdobramentos da aprovação da Lei n. 5026/2009 e do Decreto n. 30780/2009 nas políticas de esportes e lazer da Prefeitura da Cidade do Rio de Janeiro, mais especificamente do seu programa "Vilas Olímpicas".

Esses aparatos jurídicos viabilizaram a qualificação de organizações privadas sem fins de lucros (juridicamente nomeadas como associações ou fundações e vulgarmente conhecidas como "terceiro setor"), como Organizações Sociais. Desse modo, permitiram à municipalidade estabelecer contratos de gestão com tais organismos para executar políticas sociais nas áreas "dirigidas ao ensino, à pesquisa científica, ao desenvolvimento tecnológico, à proteção e preservação do meio ambiente, à cultura, à saúde e ao esporte [...]" (RIO DE JANEIRO, 2009a, p. 1 - grifo nosso). A multiplicidade de campos disponíveis indica a inserção das políticas sociais, em geral, e das políticas de esportes, lazer e saúde, em específico, como campo de atuação estatal com base nos pressupostos do projeto societário capitalista neoliberal para o século XXI (MELO, 2011).

Como parte de uma pesquisa em progresso (MELO; CUNHA; ANDRADE, 2014), esse texto irá ater-se ao processo de QUALIFICAÇÃO dos organismos na sociedade civil como Organização Social (OS) por parte da Comissão de Qualificação (Coquali) da Prefeitura do Município do Rio de Janeiro para os campos de Esporte e Lazer. Traçaremos um percurso histórico, que vai da aprovação da Lei n. 5026 e da publicação do Decreto n. 30780, ambos em 2009, passando pelas qualificações (e desqualificações) de entidades como OS pela Coquali e sua posterior seleção para gerir os equipamentos municipais. As questões que orientaram esse trabalho foram:

a) Por que a Lei n. 5026 e o Decreto n. 30780 representaram um passo adiante na estruturação da privatização da ação estatal no âmbito das políticas sociais? Como tal questão está intimamente ligada ao avanço do projeto neoliberal no Brasil?

b) Quais foram e como se deu o percurso de qualificação das OS para o campo do esporte e lazer pela Prefeitura do Rio de Janeiro?

A opção teórico-metodológica será a densa análise da Lei n. 5026 e do Decreto n. 30780, além do debate da conjuntura e da correlação de forças entre as classes sociais, em nível nacional e internacional, que favoreceram esse avanço privatista no tocante à ação estatal no campo das políticas sociais. Os dados acerca das organizações sociais, processos de qualificação e seleção das OS para gerir os equipamentos foram obtidos no Diário Oficial do Município do Rio de Janeiro, sendo as deliberações da Coquali localizadas na seção da Secretaria da Casa Civil. Nossa análise 


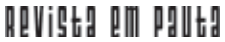

\} AS VILAS OLÍMPICAS NA CIDADE - MELO, M. P.; ANDRADE, G. M.; CUNHA, M. B. \}

DOI: $10.12957 /$ REP.2016.27866

terá como foco os documentos que contêm as qualificações ou tentativas de qualificações de entidades do campo dos esportes e lazer.

A relevância desse debate será a de lançar luz a aspectos administrativos da relação entre Estado e organismos na sociedade civil para implementação de políticas sociais de esporte e lazer. Reafirmamos que estamos diante da expressão concreta do projeto neoliberal de sociedade, com a utilização de organismos privados na execução das políticas sociais, como deixam claro seus mais incontestes apologistas (BANCO MUNDIAL, 1997; 2000; ONU, 2003; BRASIL, 1995; 2010).

\section{O chamado terceiro setor nos anos de neoliberalismo e as políticas de esporte}

A mudança no projeto neoliberal, mantendo seus aspectos dinâmicos intactos, tem recebido diversas denominações. Seja capitalismo neoliberal de terceira via (NEVES, 2010), seja social-liberalismo (CASTELO, 2013), o que há em comum é a perspectiva de manter em funcionamento a versão mais atual da exploração e dominação burguesa. O desembarque desse projeto na América Latina dos anos 1990 deu-se, sobretudo, pelas mãos de partidos denominados socialdemocratas, dos trabalhadores, ditos socialistas, com a cooptação de intelectuais orgânicos individuais e coletivos que, em algum momento, chegaram a cerrar fileiras nas lutas dos trabaIhadores (NEVES, 2010; CASTELO, 2013).

Essa expressão renovada do projeto neoliberal insiste numa resignificação da atuação estatal em diversos âmbitos. Junto às políticas privatistas do projeto neoliberal original, novas formas entram na disputa política, até mesmo com vistas a dirimir profundas resistências. O campo das políticas sociais observa isso com ênfase programática nas chamadas parcerias entre Estado e organismos na sociedade civil.

Granemann (2007) afirma que as políticas sociais na atualidade, diferente dos anos de ouro do capitalismo mundial, deixam de ser centrais à dinâmica de acumulação e realização de lucros. Contrariamente, tornamse uma barreira, na medida em que exigem direcionamentos do fundo público para atender às demandas da classe trabalhadora. É esse quadro explicativo que possibilita compreender como uma série de ataques às conquistas dos trabalhadores, em diversos países, é levada adiante. A privatização das políticas sociais, nas suas mais variadas formas e mecanismos, é parte central desse quadro.

É possível perceber uma intensa e direcionada atividade políticopedagógica dos organismos internacionais, como Sistema ONU e Banco Mundial, no sentido de difundir as concepções do chamado terceiro setor e da nova sociedade civil participativa e colaboradora. Ou seja, um projeto 


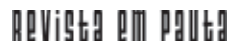

\} AS VILAS OLÍMPICAS NA CIDADE - MELO, M. P.; ANDRADE, G. M.; CUNHA, M. B. \}

DOI: $10.12957 /$ REP.2016.27866

mundial de reforma neoliberal da aparelhagem estatal. Essa militância ganhou grande intensidade a partir dos anos 1990.

O Relatório do Desenvolvimento Mundial (RDM) do Banco Mundial, de 1997, representou mais uma tentativa pedagógica de espraiar sua concepção de mundo. Este relatório, intitulado o Estado num mundo em transformação, buscou contrapor-se positivamente às teses vulgares do chamado Estado mínimo. Sem pretender contestar radicalmente tal tese, busca alertar acerca de um novo papel do Estado no capitalismo para o século XXI. Isso levou às campanhas em torno do aumento "[...] da capacidade do Estado - definida como a capacidade de realizar e promover ações coletivas de maneira eficiente" (BANCO MUNDIAL, 1997, p. 3 - grifo original), uma vez que:

[...] sem um Estado efetivo, o desenvolvimento- econômico, social e sustentável- é impossível. Reconhece-se cada vez mais que um Estado efetivo - não um Estado mínimo - é essencial para o desenvolvimento econômico e social, mais, porém, como um parceiro e facilitador do que como diretor. Os Estados devem complementar os mercados, e não substituí-los. (BANCO MUNDIAL, 1997, p. 18).

Tal movimento sempre esteve relacionado à atualização do ideário de um Estado mínimo de novo tipo, que sofreria um ajuste de suas funções "[...] à sua capacidade", visto que o "[...] Estado deve concentrar a sua capacidade nas tarefas que pode e deve executar" (BANCO MUNDIAL, 1997 , p. 3). Para tal, uma das proposições seria:

adotar um enfoque pluralista na prestação de serviços: permitir a participação privada, concentrando ao mesmo tempo a participação pública direta na provisão de bens e serviços genuinamente coletivos embora [...] os governos possam também subsidiar o consumo de bens por parte dos grupos carentes, mesmo quando os rendimentos sejam totalmente privados. (BANCO MUNDIAL, 1997, p. 56).

No RDM de 2000/2001 - um único documento abarcando o referido biênio - o Banco Mundial (2000) tem como tema "A luta contra a pobreza". São recorrentes a ideia de que a proliferação de organismos na sociedade civil, supostamente representativos dos setores mais empobrecidos dos trabalhadores, atuando na prestação de serviços, poderia cumprir um papel de relevo no controle dos serviços e dos gastos em tempos de crise.

Continuando nesse papel pedagógico de reforço do projeto capitalista neoliberal da Terceira Via, o RDM 2000 defende que a luta contra pobreza deverá incluir programas "que enfatizem resultados e sejam elaborados com a participação da sociedade civil e agentes do setor privado" (BANCO MUNDIAL, 2000, p. 12). Aqui explicita-se tanto a atuação do chamado terceiro setor quanto os princípios da responsabilidade social 


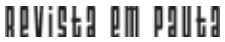

\} AS VILAS OLÍMPICAS NA CIDADE - MELO, M. P.; ANDRADE, G. M.; CUNHA, M. B. \}

DOI: $10.12957 /$ REP.2016.27866

empresarial. Tanto é que o RDM faz um alerta às frações financeiras do capital acerca de sua atuação e da necessidade de "[...] manter um diálogo aberto com organizações da sociedade civil, particularmente as que representem os pobres" (BANCO MUNDIAL, 2000, p. 12). Para o RDM (BANCO MUNDIAL, 2000, p. 12), "as empresas multinacionais também podem empreender ações, tais como a adoção de práticas éticas de investimentos e códigos de trabalho, para promover a autonomia de grupos pobres".

Concordamos com Martins et al. (2010, p. 150) quando mostram que tal concepção tem sido fundamental ao conjunto da classe burguesa em sua tarefa educativa. Assim:

Com efeito, difunde-se com o novo senso-comum que ao 'novo Estado' cabe estimular ações e se apresentar como 'parceiro' do mercado e do chamado 'terceiro setor' em projetos desenvolvimento econômico e social, construindo, desse modo, a 'sociedade de bem-estar'. Cabe, finalmente, em tempos de redefinição das relações de poder no plano nacional e internacional, ao Estado educar para a cultura cívica, para a nova sociabilidade e para os valores que the servem de esteio.

Cumpre registrar que não se trata de uma suposta ingerência contrária à perspectiva do bloco no poder nos países periféricos, os quais sofreriam imposições desses organismos internacionais. Sem anuência e operacionalidade das classes dominantes internas não há como implementar determinada concepção sob a forma de políticas concretas em diversas áreas. A apresentação dos organismos internacionais como únicos responsáveis pela execução de elementos caros ao projeto neoliberal de sociedade serve para tirar a responsabilidade das frações das classes dominantes domésticas em cada formação social. Trata-se de políticas inconcebíveis sem uma forte ação de sujeitos políticos internos, sob a forma de partidos, intelectuais orgânicos como as empresas de comunicação - e os especialistas/ comentadores/analistas que defendem em jornais escritos e televisivos visões de mundo favoráveis a esse conjunto de determinações.

Com a eleição de Fernando Henrique Cardoso/Partido da Social Democracia Brasileira (PSDB) em 1994, as relações entre organismos na sociedade civil e Estado começam a se intensificar. No início do Governo Cardoso (1995), foi criado o Ministério da Administração e da Reforma do Estado (Mare) para promover a reforma da aparelhagem estatal quanto à sua estrutura e funcionamento, tendo como titular Luiz Carlos Bresser Pereira. Percebe-se na documentação produzida pelo Mare e pela Presidência da República (BRASIL, 1995) uma ênfase constante no que era chamado de modernizar a administração pública brasileira, com vistas à adoção de um modelo intitulado de administração pública gerencial. No segundo mandato PSDB/Cardoso (1999-2002) foram sistematizadas as políticas sociais sob a égide do neoliberalismo de terceira via. A necessidade de adequar 


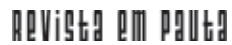

\} AS VILAS OLÍMPICAS NA CIDADE - MELO, M. P.; ANDRADE, G. M.; CUNHA, M. B. \}

DOI: $10.12957 /$ REP.2016.27866

a legislação para potencializar tais ações e, ao mesmo tempo, sem poder alterar drasticamente o regime jurídico no tocante ao imenso universo das entidades sem fins de lucro, teve como desdobramento a criação de dois títulos para entidades já existentes que estabeleceriam contratos com o Estado: Organizações Sociais (OS, Lei n. 9637 de 15 de maio de 1998) e Organizações da Sociedade Civil de Interesse Público (Oscip, Lei n. 9790 de 23 de março de 1999).

A Lei Federal das OS permitiu aos executivos qualificarem entidades com atividades nas seguintes áreas: ensino, pesquisa científica, desenvolvimento tecnológico, proteção e preservação do meio ambiente, cultura e saúde. Já as legislações de OS nos estados e sobretudo nos municípios introduziram novas áreas. $\mathrm{Na}$ análise trazida pelo Ministério do Planejamento (BRASIL, 2010), identificaram-se as seguintes áreas adicionais: desenvolvimento institucional, trabalho, educação profissional, esporte, defesa do consumidor, desenvolvimento econômico, agricultura e abastecimento, defesa do patrimônio, desenvolvimento científico e tecnológico no campo da informática, ensino de turismo e hotelaria, lazer e recreação, prestação de serviços sociais, religião e turismo.

Uma questão candente nesse debate é justamente onde radicariam as inovações trazidas por tais legislações, uma vez que já havia instrumentos legais no aparato jurídico que permitissem o recebimento de recursos por parte de organizações na sociedade civil, como atesta a relação existente entre as Apaes, as escolas de samba, os clubes esportivos, as chamadas ONGs e as associações de diversos tipos. A chave está na possibilidade de manutenção de relações prolongadas para além das restrições trazidas pelos chamados convênios - mecanismo anterior (BRASIL, 2010). Essas relações prolongadas na prestação de serviços - apologeticamente chamadas no documento do Governo Federal (BRASIL, 2010, p. 47) de "[...] atividades de interesse público, especialmente nas áreas de prestação de serviços sociais diretamente aos cidadãos" - implicam a ampliação e o aprofundamento do modelo de funcionamento do Estado pregado pelos intelectuais orgânicos dominantes.

É nesse contexto que ganham mais força os clamores pela participação do chamado terceiro setor, apresentado como outra esfera da vida em sociedade, diferente de Estado e de mercado. Estariam incluídas, no chamado terceiro setor, organizações não governamentais (ONGs), instituições filantrópicas, fundações empresariais e associações comunitárias. Tanto jurídica quanto sociologicamente, o termo terceiro setor não possui base teórica para se legitimar ou sustentar. Isso quer dizer que este busca expressar processos sociais não condizentes com a realidade social. Não há primeiro, segundo ou terceiro setor, e sim organizações estatais ou privadas (sendo lucrativas ou não).

Através do incentivo direto ou indireto à participação de organismos privados na execução de políticas públicas, o bloco no poder se 


\section{peVistg aाm paltg}

\} AS VILAS OLÍMPICAS NA CIDADE - MELO, M. P.; ANDRADE, G. M.; CUNHA, M. B. \}

DOI: $10.12957 /$ REP.2016.27866

torna elemento central na consolidação desse processo. Longe de concordarmos com a tese de que o Estado se ausenta para que organismos privados assumam a execução, apontamos que isso é parte central do processo, conjugado com uma série de iniciativas correlatas, como a precarização no mundo trabalho e a diminuição da capacidade executora do Estado. A emergência de tantas ações sociais privadas indica uma nova estratégia educativa da burguesia brasileira e mundial para educar o consenso de amplos setores da população. Fica explícito que, longe de retirar-se, o bloco no poder, mediante uma série de incentivos legais como financiamento direto ou isenções fiscais, conduz o Estado a ser partícipe de todo o processo. Afirmar que tais organizações atuariam num suposto vácuo deixado pela omissão estatal, ou que justamente por isso é que tais organismos se veem impelidos a agir, significa não situar a emergência da atuação de organismos privados como pretensos substitutos da aparelhagem estatal na execução de políticas públicas como parte central do projeto capitalista neoliberal em nosso tempo, como bem demonstram as experiências presentes em Neves (2010).

Cumpre registrar que ao longo dos anos Lula da Silva/PT (20032010) esse processo de atuação das chamadas ONGs recebeu um poderoso incremento. Não apenas não foram revogadas as legislações, como, além disso, partidos aliados à frente de estados e municípios criaram suas legislações de regulamentação de atuação dessas organizações na oferta de políticas sociais por meio de convênios e contratos com entes públicos. Não obstante, tornou-se o modus operandi de execução de políticas sociais do Governo Federal por meio de seus ministérios.

Os processos de aproximação entre Estado e entidades na sociedade civil, na gestão de políticas sociais trazidas pelas leis federais, estaduais e municipais das OS e Oscip, possibilitou um desmonte de entidades com atuações críticas e independentes e, ao mesmo tempo, a expansão de aparelhos privados de hegemonia já criados com fito colaboracionista. O gerenciamento da força de trabalho passou a ser realizado não somente pelas empresas privadas clássicas; além disso, organismos na sociedade civil com vultosos orçamentos advindos de contratos governamentais tornaram-se direta ou indiretamente grandes empregadores.

O conjunto de questões que marcam o projeto capitalista neoliberal incide, de forma intensa, no campo dos esportes e, mais especificamente, nas políticas sociais de esportes. Questões como contingenciamento de recursos, focalização das políticas, atuação sob a lógica das chamadas parcerias com organismos na sociedade civil na execução das políticas, difusão do chamado trabalho voluntário e promoção da chamada responsabilidade social empresarial encontram nas ações esportivas um rico campo de atuação.

No que tange às políticas sociais de esporte, o papel do Estado capitalista não se diferencia dos outros campos com muita substância. A oferta de políticas esportivas será diretamente proporcional ao estágio da corre- 


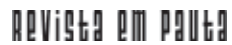

\} AS VILAS OLÍMPICAS NA CIDADE - MELO, M. P.; ANDRADE, G. M.; CUNHA, M. B. \}

DOI: $10.12957 /$ REP.2016.27866

lação de forças entre as classes sociais em luta. Nesse sentido, a tripla dimensão que acompanha as políticas sociais nas sociedades capitalistas - a) reprodução da força de trabalho e aumento da produtividade do trabalho; b) mecanismo de obtenção do consenso dos trabalhadores e c) mecanismos de melhoria das condições de vida dos trabalhadores (NETTO, 2005) incidem também no debate acerca das políticas de esportes. Tanto numa dimensão de reprodução físico-emocional das energias dos trabalhadores como praticantes e/ou espectadores esportivos, quanto na difusão da meIhoria das condições de vida e de ascensão social via esporte, passando pela real possibilidade de melhor qualidade de vida e formação humana pela incorporação cotidiana dos esportes e/ou atividade física na vida dos trabalhadores, as políticas sociais esportivas trazem em si essas múltiplas dimensões. O que irá definir qual ou quais dessas dimensões se fará ou farão presentes nos programas de esportes será certamente o grau de consciência das relações de força entre e intraclasses sociais. O potencial pedagógico emancipatório ou conservador presente nas manifestações esportivas será determinado pelo projeto histórico das classes sociais e sua efetivação no bojo de suas lutas.

Fazendo parte expressamente do projeto societário do bloco no poder capitaneado pelo PT, houve forte incremento das condições concretas de atuação do chamado terceiro setor nas políticas de esportes, tanto nos governos Lula da Silva quanto nos governos Rousseff.

O relatório da I Conferência Nacional de Esporte em 2004 expressa a contradição de um governo que se arvora no passado de partidos e movimentos sociais que um dia cerraram as fileiras da classe trabalhadora. A lógica das chamadas parcerias é destacada. No tocante ao "Esporte Educacional", é destacado que os investimentos estatais devem garantir:

[...] aproveitamento de espaços físicos já existentes nos municípios e estados, com parcerias públicas e privadas que promovam a ampliação da oferta da prática esportiva para alunos e alunas das escolas públicas e comunidade em geral; [...], f) criação de fundos e incentivos fiscais orientados, principalmente àqueles que desenvolvem programas e projetos sociais e ações interdisciplinares, integradas com outros setores sociais, voltados ao esporte educacional. (BRASIL, 2004a, p. 14).

Um aspecto ressaltado no documento Política nacional de esporte (BRASIL, 2005) que merece maior destaque é a ação articulada entre Ministério do Esporte e Secretaria Especial dos Direitos Humanos, com vistas a possibilitar "[...] o financiamento de projetos sociais por meio de incentivo fiscal legal" (BRASIL, 2005, p. 15). Isso implica que os chamados projetos esportivos sociais possam receber recursos via Fundo Nacional para a Criança e Adolescente (FNCA), a partir da criação da chamada Comissão de Chancela aos Projetos Esportivos Sociais, no interior do Conselho Nacional dos Direitos da Criança e do Adolescente (Conanda). Essa co- 


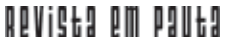

\} AS VILAS OLIIMPICAS NA CIDADE - MELO, M. P.; ANDRADE, G. M.; CUNHA, M. B. \}

DOI: $10.12957 /$ REP.2016.27866

missão no interior do referido conselho poderá conferir chancela a programas de esportes para jovens e crianças, desde que registrados no Conselho Municipal de Direitos da Criança e Adolescente da cidade-sede. Desse modo, indica-se que os organismos na sociedade civil ou órgãos estatais contemplados com a chancela têm possibilidade de obter recursos com o que o edital chamou de "doadores", que podem ser pessoas físicas ou jurídicas (BRASIL, 2004b).

No sítio do Ministério do Esporte esse elemento ganha destaque como uma das ações vinculadas à Secretaria Nacional de Esporte Educacional, sob a alcunha de "Projetos Esportivos Sociais". Contando com um amplo aparato orientador das ações a serem tomadas pelos demandantes de recursos públicos via mecanismos de contribuição de empresas e/ou pessoas físicas ao Fundo Nacional de Criança e Adolescência, é possível encontrar manuais de incentivo fiscal, orientação para doações, toda legislação concernente a isso e também os relatos de algumas palestras, bem como os programas que foram contemplados. Como é exposto no sítio do Ministério do Esporte:

\begin{abstract}
Diante de um país em que os problemas sociais são a principal preocupação dos governantes, temos o dever moral e ético de exercermos a Responsabilidade Social, principalmente no que tange à democratização do acesso ao esporte e ao lazer para a infância e a adolescência. [...] Reconhecido sua importância [do esporte e do lazer], esse tema é constante nas discussões entre o Governo Federal e organismos internacionais como a UNESCO, UNICEF e ONU. É sabido que as classes menos favorecidas sempre viram o esporte como uma forma de galgar posições na vida, de superar barreiras da ascensão social e de, potencialmente, obter sucesso. Comprovadamente, na atualidade, sabemos que é muito mais que isso...Fazer e produzir esporte é gerar mais saúde, mais equilíbrio, e é principalmente um importante instrumento para capacitar pessoas a ingressarem construtivamente na sociedade. A Ação Projetos Esportivos Sociais dá oportunidade para ampliarmos o atendimento da demanda sócio-esportiva do país, firmando novas parcerias com os mais diversos setores, que engajados visam contribuir efetivamente para o combate das mazelas de nossa sociedade, e que consequentemente irão agregar valores inestimáveis às suas marcas, e inerentes a essa Ação, como: Responsabilidade Social, Sustentabilidade e Governança. (BRASIL, 2011. n.p. - grifos no original).
\end{abstract}

Tal mecanismo, louvado pelo Ministério do Esporte como possibilidade de financiar as políticas (estatais) e programas (privados) de esportes para jovens e crianças, representa um passo adiante na privatização dessas políticas. A adoção explícita da responsabilidade social por parte do Governo Lula da Silva/PT mostra que sequer há ou houve um enfrentamento pedagógico dessa concepção tão cara à dominação burguesa. Os objetivos específicos do programa "Projetos Esportivo-Sociais" são: 
Democratizar a prática esportiva e de lazer como direito de todos. Capacitar crianças e adolescentes a ingressarem positivamente na sociedade. Gerar mais saúde, equilíbrio psicológico, físico e motor. Possibilitar que o esporte seja o ponto de partida para a ascensão social, através da descoberta e aproveitamento de talentos. Agregar conceitos de Responsabilidade Social aos agentes envolvidos no Projeto. (BRASIL, 2011, n.p.).

Há uma defesa da necessidade de diversificação e dinamização das fontes para os programas e projetos de esportes no Brasil. Segundo o Ministério do Esporte (BRASIL, 2005), as fontes para financiar essas políticas são o orçamento da união, recursos específicos para formação esportiva, recursos oriundos da Lei Agnelo/Piva, da Bolsa Atleta e da Loteria TimeMania. Além destes, também são destacadas outras fontes, como as "[...] constituídas por parcerias com empresas na busca de captação de recursos, com incentivo fiscal pelo CONANDA, através do Fundo de Incentivo a Projetos Esportivos Sociais" (BRASIL, 2005, p. 21).

\section{A Lei n. 5026, o Decreto n. 30780 e as OS}

Em maio de 2009 - primeiros meses da administração de Eduardo Paes-PMDB - a Câmara de Vereadores do Rio de Janeiro transformou em lei um projeto enviado pelo Executivo municipal que "[...] dispõe sobre a qualificação de entidades [privadas sem fins de lucro] como Organizações Sociais e dá outras providências" (RIO DE JANEIRO, 2009a, p. 1). Apenas 14 dias depois da aprovação é publicado o Decreto n. 30780-2009 (RIO DE JANEIRO, 2009b), que regulamenta a Lei n. 5026 e explica em detalhes os conceitos e procedimentos de qualificação de OS, o contrato de gestão, os certames, os programas de trabalho e outros elementos da execução propriamente dita. Considerando o breve tempo da referida administração por parte desse bloco no poder, é possível inferir que esse projeto é prioritário ao projeto político em questão.

Especificamente no tocante ao contrato de gestão - nome dado ao tipo de convênio a ser estabelecido entre a municipalidade e a entidade qualificada como OS -, o parágrafo 1 (§ 1) do artigo $8^{\circ}$. do Decreto n. 30780 (RIO DE JANEIRO, 2009b) afirma a necessidade de publicação no Diário Oficial do município (do Rio de Janeiro) à prestação de contas referentes ao exercício financeiro (anual), bem como o balanço e demais prestações de contas da OS.

No contrato de gestão constará o programa de trabalho, assim como as metas a serem alcançadas e seus respectivos prazos. Já no inciso $\mathrm{V}$ consta a duração do contrato, que em seu início é de dois anos, podendo ser renovado por duração igual e posteriormente por mais um ano, se as metas estipuladas atingirem um mínimo de $80 \%$. Além disso, deve constar 


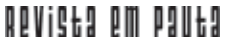

\} AS VILAS OLÍMPICAS NA CIDADE - MELO, M. P.; ANDRADE, G. M.; CUNHA, M. B. \}

DOI: $10.12957 /$ REP.2016.27866

"o orçamento, o cronograma de desembolso e as fontes de receita para a sua execução" (RIO DE JANEIRO, 2009a, p. 6).

A seção II do decreto estabelece os procedimentos para a convocação pública para parcerias, sendo esta publicada em Diário Oficial. Além das metas (inciso III) e do orçamento (inciso IV), estabelece os critérios para a seleção da OS e designa a comissão de seleção, bem como a exigência de um percentual não apontado de trabalhadores voluntários. Caso haja uma única entidade interessada, o art. 13 afirma que "o Poder Público poderá celebrar com essa entidade o contrato de gestão" (RIO DE JANEIRO, 2009b, p. 8), desde que a mesma cumpra somente as exigências da proposta de trabalho, desconsiderando outras questões relativas ao processo de seleção. Na subseção I, que trata da comissão de seleção, afirma que esta será constituída por três membros indicados por um "secretário competente", mas não explica como se dá o processo de escolha dos membros da comissão.

Voltamos especificamente à obrigação de determinado percentual de trabalhadores voluntários no plano de trabalho da OS que pleitear participação nas seleções para gerir equipamentos municipais. Isso significa que a existência do voluntariado deixa de ser uma opção e passar a ser, na execução das políticas sociais via OS no Rio de Janeiro, uma obrigação. Por mais contraditória que seja obrigar alguém a se voluntariar - estranho até mesmo na hora de redigir -, é disso que se trata a obrigação de determinado percentual no âmbito do Decreto n. 30780-2009. Desse modo, atesta-se ser o voluntariado uma das premissas que regem a atuação do bloco no poder nos anos de capitalismo neoliberal, configurando um papel de destaque a essa forma extrema de exploração político-econômica do trabalhador (MARTINS, 2009; MELO, 2011).

O capítulo III do decreto (RIO DE JANEIRO, 2009b) trata da fiscalização e da execução dos contratos de gestão, cabendo às pastas em que ocorrem os contratos de gestão a formação de comissões de avaliação, a partir de indicações da Secretaria Municipal correspondente. Ainda é destacado que a "comissão será composta por profissionais de notória especialização" (RIO DE JANEIRO, 2009b, p.11), mas também não especifica os critérios que levariam um indivíduo a ter uma "notória especialização". Já o art. 27 reforça a obrigatoriedade da publicação dos balanços e relatórios financeiros no Diário Oficial do município, assim como devem ser analisados pelo Tribunal de Contas do município.

O capítulo IV é divido em duas seções. A primeira, que trata do repasse de recursos, tem como destaque o art. 29. Este autoriza as Organizações Sociais a captarem recursos de organismos privados, escancarando as portas à privatização das políticas sociais via financiamento privado. Captação de recursos de que forma? De quem? Com quais interesses? Por que uma pessoa física ou empresa doaria recursos para uma OS que executa uma política social? São incômodos questionamentos que necessitam ser feitos. 
$\mathrm{O}$ art. 17 da Lei n. 5026, peremptoriamente, afirma ser responsabilidade das OS publicarem na:

[...] imprensa e no Diário Oficial do Município, no prazo máximo de noventa dias contados da assinatura do contrato de gestão, regulamento próprio contendo os procedimentos que adotará para a contratação de serviços e obras necessárias à execução do contrato de gestão, bem como para compras com emprego de recursos provenientes do Poder Público. (RIO DE JANEIRO, 2009a, p. 4).

Isso é acrescido pela descrição no Decreto n. 30.780/2009, de que a própria secretaria referente aos respectivos contratos de gestão em cada caso concreto publicará o "[...] o extrato do contrato, após sua assinatura, no Diário Oficial, e disponibilizará seu inteiro teor, no Portal da Prefeitura do Município do Rio de Janeiro, na internet" (RIO DE JANEIRO, 2009b, p. 10 - grifo nosso).

Mesmo tratando-se de informações as quais, em geral, relutam em disponibilizar, sobretudo quanto à vida financeira das entidades e usos de recursos públicos, parece não restar dúvida de que há um campo aberto à séria pesquisa em políticas públicas e à materialização da nova relação entre Estado e sociedade civil na execução das políticas sociais ampla e publicamente assentadas nos pressupostos neoliberais.

\section{O Programa Vilas Olímpicas e as Organizações Sociais}

O termo "Vila Olímpica" foi consagrado a partir da experiência da Escola de Samba Mangueira. Vila Olímpica tornou-se sinônimo de projeto de esportes e lazer em bairros pobres e favelas. No imaginário coletivo presta-se a duas funções: a primeira, preparar as gerações futuras de atletas, sendo uma espécie de "celeiro" de novos talentos; e a segunda representaria uma forma de "afastar" os jovens da criminalidade e das drogas através da prática esportiva (MELO, 2005).

Esses sentidos e "funções" que teriam as Vilas Olímpicas são atribuídos diariamente nos principais meios de comunicação e também em manifestações públicas de seus dirigentes. Longe de aceitá-las sem questionamento, é importante compreendermos como esse discurso é bem recebido na sociedade, representando quase que uma fórmula inconteste: "jovem que pratica esporte não se envolve com drogas", ou, ainda, "o esporte é importante para afastar os jovens do mundo do crime". A partir de argumentos salvacionistas, as Vilas Olímpicas são pensadas como um modelo de política pública de esporte para a juventude pobre no Rio de Janeiro, ganhando grande destaque no fim dos anos 1990 e início dos anos 2000 (MELO, 2005). A partir daí, a Prefeitura do Rio de Janeiro encampa o progra- 


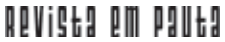

\} AS VILAS OLÍMPICAS NA CIDADE - MELO, M. P.; ANDRADE, G. M.; CUNHA, M. B. \}

DOI: $10.12957 /$ REP.2016.27866

ma pioneiro localizado na favela da Maré - posteriormente chamado Vila Olímpica da Maré - e vai ampliando para outros locais na cidade.

Para a instalação desses equipamentos foram priorizadas as regiões que não tinham equipamentos de esporte e lazer. Em geral, a estrutura das Vilas Olímpicas consiste em:

\begin{abstract}
piscina semi-olímpica, quadra poliesportiva coberta, pista de atletismo, campo de futebol de grama natural ou sintética, salas de atividades como balet, artes marciais, ginástica, atividades para idosos, além de parque infantil e churrasqueira. Algumas vilas possuem também quadras de tênis, de vôlei de praia e pista de skate. Há também espaços de apoio: administração, secretaria, vestiários, sanitários, salas de coordenação e de professores, auditório, departamento médico e depósitos ${ }^{1}$.
\end{abstract}

No que diz respeito às práticas esportivas realizadas nas vilas, temos uma mescla de sentidos atrelados. Os atendimentos são feitos a um público bem diversificado, englobando desde pessoas da comunidade local e estudantes do ensino fundamental da rede pública municipal de ensino a pessoas idosas e com deficiência.

No início da década de 2000, as Vilas Olímpicas eram geridas a partir de convênios entre a PMRJ e algumas federações esportivas, cabendo a estas a contratação de profissionais administrativos e pedagógicos (MELO, 2005). Isso foi objeto de diversas polêmicas e questionamentos, tanto do Ministério Público quanto do Tribunal de Contas do Município (RIO DE JANEIRO, 2004).

$\mathrm{Na}$ atualidade (fevereiro de 2015), a PMRJ aponta em sua página na internet ${ }^{2}$ a existência de 17 Vilas Olímpicas na cidade do Rio de Janeiro, com suas datas de inauguração ao lado, a saber: 1) Centro Esportivo Miécimo da Silva, em 1982, no bairro de Campo Grande; 2) Vila Olímpica da Mangueira, em 1987, na Mangueira3; 3) Vila Olímpica da Maré, em 2000, no bairro de mesmo nome; 4) Vila Olímpica Carlos Castilho, em 2002, no bairro de Ramos (Complexo do Alemão); 5) Vila Olímpica Mestre André, em 2002, no bairro de Padre Miguel; 6) Vila Olímpica Clara Nunes, em 2002, no bairro de Fazenda Botafogo; 7) Vila Olímpica Jornalista Ary de Carvalho, em 2003, no bairro de Vila Kennedy; 8) Ciad Mestre Candeia, em 2003, no Centro; 9) Vila Olímpica Oscar Schmidt, em 2004, no bairro de Santa Cruz; 10) Vila Olímpica da Gamboa, em 2004, no bairro de mesmo nome; 11) Vila Olímpica Professor Manoel José Gomes Tubino, em 2010, no bairro de Mato Alto (Jacarepaguá); 12) Vila Olímpica Félix Mielli Venerando, em 2011, em Honório Gurgel; 13) Vila Olímpica Arthur

\footnotetext{
${ }^{1}$ Ver http://www.cidadeolimpica.com.br/projetos/vilas-olimpicas/.

${ }^{2}$ http://www.rio.rj.gov.br/web/smel/listaconteudo?search-type=vilasolimpicas

${ }^{3}$ Até 2011 era administrada pela Escola de Samba Estação Primeira de Mangueira com financiamento privada e de empresas estatais. Depois, como veremos, passou a integrar o corpo de Vilas Olímpicas Municipais.
} 


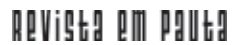

\} AS VILAS OLÍMPICAS NA CIDADE - MELO, M. P.; ANDRADE, G. M.; CUNHA, M. B. \}

DOI: $10.12957 /$ REP.2016.27866

da Távola, em 2012, em Vila Isabel; 14) Vila Olímpica Mané Garrincha, em 2012, no Caju; 15) Vila Olímpica do Encantado, em 2013, no Encantado; 16) Vila Olímpica Dr. Sócrates Brasileiro, em 2014, em Pedra de Guaratiba; 17) Vila Olímpica do Vidigal, no Vidigal.

A partir de agora iremos apresentar os percursos de qualificação como OS e a posterior escolha para gestão dos equipamentos "Vilas Olímpicas". Instituída a Comissão de Qualificação (Coquali), a prefeitura realizou a primeira qualificação de entidades, publicada em 17 de agosto de 2009, com a deliberação 4 (COQUALI, 2009a). São listadas nove entidades de diversos campos que apresentaram pleito de qualificação, sendo que apenas três obtiveram deferimento - uma, inclusive, do campo de esporte e lazer (Movimento Cultural Social - CNPJ: 03.852.999/000195). Na deliberação 5 temos a qualificação do Centro Comunitário Lídia dos Santos - Ceaca-Vila, em setembro de 2009, para o campo de esporte e lazer (COQUALI, 2009b). Nas posteriores, nenhuma entidade do campo de esporte e lazer foi qualificada.

Em novembro do mesmo ano ocorreram três deliberações (13 no dia 3, 14 no dia 10 e 15 no dia 11). Percebemos um aumento no interesse das entidades em se qualificarem no campo esporte e lazer. Já Crescer Com Meta, Solazer - Clube dos Excepcionais, Ibeea, Centro de Formação Alzira de Aleluia buscaram a sua qualificação, mas somente a última conseguiu na deliberação 14 (COQUALI, 2009d). A Solazer - Clube dos Excepcionais tentou por duas vezes, porém, ambas as tentativas foram negadas por falta de documentos (COQUALI, 2009c; 2009d).

Em dezembro de 2009 foram realizadas mais seis deliberações da Coquali. Na deliberação 20, de 29 de dezembro de 2009, o Ibeea se junta ao grupo formado por MCS, Ceaca-Vila e Centro de Formação Alzira de Aleluia. Novamente, o pedido de qualificação da Solazer - Clube dos Excepcionais é negado (COQUALI, 2009f). A qualificação da Associação Crescer com Meta também foi negada (COQUALI, 2009e). Terminamos 2009 com quatro OS qualificadas no campo de esporte e lazer e, com isso, foram declaradas aptas a participar de certames para gestão de alguma Vila Olímpica.

Em 2010 foram 15 deliberações da Comissão de Qualificação. No campo esporte e lazer, as entidades qualificadas passaram de quatro, em 2009, para sete ao longo do ano. A deliberação 24, de 11 de março, qualifica as instituições Associação Crescer com Meta e Solazer - Clube dos Excepcionais (COQUALI, 2010a). Em abril, a União Esportiva Vila Olímpica da Maré (Uevom) tem a sua qualificação negada por falta de documento na deliberação 26, não sendo explicitado que documento era esse. A mesma só consegue a sua qualificação no mês de agosto do mesmo ano, com a deliberação 32 .

Em relação às outras entidades que sofreram recusas, a Uevom levou mais tempo para obter a qualificação num novo pleito (COQUALI, 


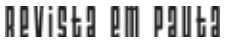

\} AS VILAS OLIMMPICAS NA CIDADE - MELO, M. P.; ANDRADE, G. M.; CUNHA, M. B. \}

DOI: $10.12957 /$ REP.2016.27866

2010b; 2010c). A partir daí, havia sete OS qualificadas para o campo esporte e lazer, com seus respectivos CNPJs (COQUALI, 2011a). São elas: 1) Associação Crescer com Meta (05.515.363/000183); 2) Centro Comunitário Lídia dos Santos (Ceaca-Vila - 29.014.008/0001-99); 3) Centro de Formação Profissional Alzira de Aleluia (06.065.394/0001-42); 4) Instituto Brasileiro de Estudos Especializados e Avançados (Ibeea - 04.641.617/0001-47); 5) Solazer - Clube dos Excepcionais (28.008.530/0001-03); 6) Movimento Cultural Social, já referida; e 7) União Esportiva Vila Olímpica da Maré (Uevom - 03.139.962/0001-14).

Outras entidades seguiram buscando sua qualificação com o intuito de participar da gestão de equipamentos municipais em diversas áreas. No âmbito do esporte e lazer, tivemos a primeira tentativa de qualificação do Instituto Muda Mundo (07.148.342/0001-00) em abril de 2011. Esta foi recusada, pois houve necessidade de uma "complementação de documentação", ainda que na deliberação em questão não viesse explicitado qual (ou quais) documento(s) faltava $(\mathrm{m})$. $\mathrm{O}$ instituto somente se qualifica em julho do mesmo ano, ou seja, três meses após a primeira tentativa (COQUALI, 2011b; 2011c). No fim de 2011, com a deliberação 56, de 23 de dezembro (COQUALI, 2011d), a Associação Ecos - Espaço, Cidadania e Oportunidades Sociais (02.539.959/0001-25) é qualificada.

O Centro Brasileiro de Ações Sociais para Cidadania (Cebrac 03.533.879/ 0001-25) consegue a sua qualificação em 15 de agosto de 2012, através da deliberação 74 (COQUALI, 2012d). Intrigou-nos o fato de que seu pedido de qualificação foi classificado como "em diligência" nas deliberações 61 (COQUALI, 2012b) e 67 (COQUALI, 2012c), sem que os motivos para tal classificação fossem explicitados. A Associação Treino Livre de Apoio Sociocultural (Atlas - 067.369. 421/0001-65) obtém sua qualificação com a deliberação 85, de 25 de abril de 2013 (COQUALI, 2013a).

Mas nem só de qualificações vive a Coquali. Na deliberação 60 é apresentada uma lista com entidades qualificadas com mais de cinco anos de criação que não se adequaram ao art. 19 da Lei n. 5.026. Este artigo dava um prazo de dois anos para tais entidades se adequarem às normas do art. 3 da referida lei. Assim, foram instaurados processos de desqualificação. O Ibeea foi o único, do campo esporte e lazer, a estar presente na lista (COQUALI, 2012a). O processo de desqualificação durou mais de um ano, tendo como fim a desqualificação do Ibeea em julho de 2013, na deliberação 87 (COQUALI, 2013b). Entretanto, a deliberação 97 (COQUALI, 2014b), de 17 de junho de 2014, torna sem efeito a menção feita ao Ibeea nas deliberações 60 e 87 . Desse modo, o instituto volta a figurar entre as entidades qualificadas e consequentemente a gerir a Vila Olímpica do Caju.

Na deliberação 96, de 31 de março de 2014, as entidades Brazukerê - Associação Cultural e o Instituto Rio Esporte e Lazer têm o pedido 


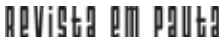

\} AS VILAS OLIIMPICAS NA CIDADE - MELO, M. P.; ANDRADE, G. M.; CUNHA, M. B. \}

DOI: $10.12957 /$ REP.2016.27866

de qualificação posto em "diligência" sem maiores explicações. Até o fim de 2014 foram efetuadas 103 deliberações da Comissão de Qualificação, sendo a última em outubro do mesmo ano - deliberação 103, de 25 de outubro de 2014 (COQUALI 2014a; 2014c).

Chegamos em 2014 com o seguinte quadro de entidades qualificadas gerindo os equipamentos Vilas Olímpicas na cidade do Rio de Janeiro: a única unidade gerida por entidade não qualificada é a Vila Olímpica Clara Nunes, no bairro (favela) Acari, que é administrada por uma entidade vinculada à Pontifícia Universidade Católica do Rio de Janeiro (PUC-Rio).

\section{Tabela de entidades qualificadas para gestão de Vilas Olímpicas}

\begin{tabular}{|c|c|c|c|}
\hline NOME ENTIDADE & VILA OLIIMPICA & LOCAL & INAUGURAÇĀO \\
\hline $\begin{array}{l}\text { Associação Treino Livre } \\
\text { de Apoio Sociocultural } \\
\text { (Atlas) }\end{array}$ & $\begin{array}{l}\text { Vila Olímpica do } \\
\text { Encantado }\end{array}$ & Encantado & 2013 \\
\hline \multirow[t]{5}{*}{$\begin{array}{l}\text { Centro Comunitário Lídia } \\
\text { dos Santos (Ceaca-Vila) }\end{array}$} & $\begin{array}{l}\text { Vila Olímpica Félix } \\
\text { Mielli Venerando }\end{array}$ & Honório Gurgel & 2012 \\
\hline & $\begin{array}{l}\text { Vila Olímpica Artur da } \\
\text { Távola }\end{array}$ & Vila Isabel & 2011 \\
\hline & $\begin{array}{l}\text { Vila Olimpica } \\
\text { Jornalista Ary de } \\
\text { Carvalho }\end{array}$ & Vila Kennedy & 2003 \\
\hline & $\begin{array}{l}\text { Centro Esportivo } \\
\text { Miécimo da Silva }\end{array}$ & Campo Grande & 1982 \\
\hline & $\begin{array}{l}\text { Vila Olimpica Oscar } \\
\text { Schmidt }^{4}\end{array}$ & Santa Cruz & 2004 \\
\hline \multirow{4}{*}{$\begin{array}{l}\text { Movimento Cultural } \\
\text { Social }\end{array}$} & Ciad Mestre Candeia & Centro & 2003 \\
\hline & $\begin{array}{l}\text { Vila Olímpica Carlos } \\
\text { Castilho }\end{array}$ & Complexo do Alemão & 2002 \\
\hline & $\begin{array}{l}\text { Vila Olímpica da } \\
\text { Gamboa }\end{array}$ & Gamboa & 2004 \\
\hline & $\begin{array}{l}\text { Vila Olimpica Mestre } \\
\text { André }\end{array}$ & Padre Miguel & 2002 \\
\hline \multirow[t]{2}{*}{$\begin{array}{l}\text { Sólazer - Clube dos } \\
\text { Excepcionais }\end{array}$} & $\begin{array}{l}\text { Vila Olímpica da } \\
\text { Mangueira }\end{array}$ & Mangueira & 1987 \\
\hline & $\begin{array}{l}\text { Vila Olimpica Prof. } \\
\text { Manoel José Gomes } \\
\text { Tubino }\end{array}$ & $\begin{array}{l}\text { Mato Alto- } \\
\text { Jacarepaguá }\end{array}$ & 2010 \\
\hline $\begin{array}{l}\text { União Esportiva Vila } \\
\text { Olimpica da Maré } \\
\text { (Uevom) }\end{array}$ & Vila Olimpica da Maré & Maré & 2000 \\
\hline $\begin{array}{l}\text { Espaço, Cidadania e } \\
\text { Oportunidades Sociais } \\
\text { (Ecos) }\end{array}$ & $\begin{array}{l}\text { Vila Olímpica Oscar } \\
\text { Schmidt }\end{array}$ & Santa Cruz & $2004^{5}$ \\
\hline $\begin{array}{l}\text { Instituto Brasileiro de } \\
\text { Estudos Especializados e } \\
\text { Avançados (Ibeea) }\end{array}$ & $\begin{array}{l}\text { Vila Olímpica Mané } \\
\text { Garrincha }\end{array}$ & Caju & 2012 \\
\hline Faculdades Católicas & $\begin{array}{l}\text { Vila Olimpica Clara } \\
\text { Nunes }\end{array}$ & Fazenda Botafogo & 2002 \\
\hline
\end{tabular}

EM PAUTA, Rio de Janeiro - $2^{\circ}$ Semestre de 2016 - n. 38, v. 14, p. 259 - 279 


\section{Conclusões (ainda caminhando)}

Este é um trabalho em progresso. Esse texto intenta abordar somente uma dimensão do processo iniciado com a aprovação da Lei das OS (Lei n. 5026-2009) na cidade do Rio de Janeiro, que culmina com a gestão dos equipamentos municipais em diversas áreas por organismos privados sem fins de lucro. Nesse texto, pretendemos demonstrar o processo de qualificação das entidades do campo do Esporte e Lazer como OS. Isso abriu as portas para que as mesmas pudessem - como de fato se verificou - estabelecer contratos de gestão para Vilas Olímpicas na Cidade Maravilhosa.

A consolidação desse caro aspecto da reforma do Estado nos moldes preconizados pelo projeto capitalista neoliberal envolve diversos passos. Da aprovação da Lei n. 5026 até a execução cotidiana dos programas municipais - em processo de escrita por esses mesmos autores - há todo um percurso. O desafio da pesquisa tem sido retomar esse caminho mediante os rastros deixados em documentos públicos. Os próximos passos serão a análise dos contratos de gestão entre a prefeitura e as OS para gerir cada unidade Vila Olímpica no Rio de Janeiro.

\footnotetext{
${ }^{4}$ De 2009 a 2011, o Caeca-Vila geriu essa Vila Olímpica. A partir daí, a entidade Ecos passou a geri-la.

${ }^{5}$ A partir de 2012.
} 


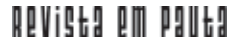

\} AS VILAS OLÍMPICAS NA CIDADE - MELO, M. P.; ANDRADE, G. M.; CUNHA, M. B. \}

DOI: $10.12957 /$ REP.2016.27866

\section{Referências}

BANCO MUNDIAL. Relatório sobre o desenvolvimento mundial, 1997: o Estado num mundo em transformação. Washington: Banco Mundial, 1997.

. Relatório sobre o desenvolvimento mundial, 2000-2001. A luta contra a pobreza. Washington: Banco Mundial, 2000.

BRASIL. Presidência da República. Plano diretor da reforma do aparelho do Estado. Brasília: Presidência da República do Brasil, 1995.

. Ministério do Esporte. Documento final da I Conferência Nacional de Esporte. Brasília: Ministério do Esporte, 2004a.

. Conselho Nacional dos Direitos da Criança e do Adolescente. Edital para inscrição de projetos esportivo-sociais. 2004b. Disponível em: <http:/ /portal.esporte.gov.br/snee/esportesocial/>. Acesso em: 24 jul. 2005.

. Política nacional de esporte. Brasília: Ministério do Esporte, 2005.

. Projetos esportivo-sociais. [2005]. Disponível em: <http://www. esporte.gov.br/snee/esportesocial/default.jsp>. Acesso em: 20 maio 2011.

. Programa esporte e lazer na cidade. [2005]. Disponível em: <http:/ /www.esporte.gov.br/sndel/esporteLazer/default.jsp>. Acesso em: 13 set. 2010.

- Ministério do Planejamento. Relações de parceria entre poder público e entes de cooperação e colaboração no Brasil. [2010]. Brasília: Ministério do Planejamento, 2010.

CASTELO, R. O canto da sereia: social liberalismo, novo desenvolvimentismo e supremacia burguesia no capitalismo dependente brasileiro. Revista Em Pauta, Rio de Janeiro, n. 31, 2013.

COQUALI. Deliberação Coquali n. 4 de 17 de agosto de 2009. Define instrução processual para qualificação de Organizações Sociais, procedimentos da Comissão de Qualificação de Organizações Sociais - Coquali [...]. Rio de Janeiro: PMRJ-Coquali, 2009a.

. Deliberação Coquali n. 5 de 2 de setembro de 2009. Dispõe sobre o parecer da Coquali quanto à solicitação de qualificação como Organização Social das entidades que menciona. Rio de Janeiro: PMRJ-Coquali, 2009b.

- Deliberação Coquali n. 13 de 30 de outubro de 2009. Dispõe sobre o parecer da Coquali quanto à solicitação de qualificação como Organização Social das entidades que menciona. Rio de Janeiro: PMRJCoquali, 2009c.

. Deliberação Coquali n. 14 de 10 de novembro de 2009. Dispõe sobre o parecer da Coquali quanto à solicitação de qualificação como Or- 


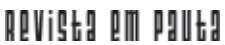

\} AS VILAS OLIIMPICAS NA CIDADE - MELO, M. P.; ANDRADE, G. M.; CUNHA, M. B. \}

DOI: $10.12957 /$ REP.2016.27866

ganização Social das entidades que menciona. Rio de Janeiro: PMRJ-Coquali, 2009d.

Deliberação Coquali n. 17 de 8 de dezembro de 2009. Dispõe sobre o parecer da Coquali quanto à solicitação de qualificação como Organização Social das entidades que menciona. Rio de Janeiro: PMRJ-Coquali, 2009e.

Deliberação Coquali n. 20 de 29 de dezembro de 2009. Dispõe sobre o parecer da Coquali quanto à solicitação de qualificação como Organização Social das entidades que menciona. Rio de Janeiro: PMRJ-Coquali, $2009 f$.

. Deliberação Coquali n. 24 de 11 de março de 2010. Dispõe sobre o parecer da Coquali quanto à solicitação de qualificação como Organização Social das entidades que menciona. Rio de Janeiro: PMRJ-Coquali, 2010 a.

. Deliberação Coquali n. 26 de 12 de abril de 2010. Dispõe sobre o parecer da Coquali quanto à solicitação de qualificação como Organização Social das entidades que menciona. Rio de Janeiro: PMRJ-Coquali, $2010 \mathrm{~b}$.

. Deliberação Coquali n. 32 de 11 de agosto de 2010. Dispõe sobre o parecer da Coquali quanto à solicitação de qualificação como Organização Social das entidades que menciona. Rio de Janeiro: PMRJ-Coquali, 2010c.

Deliberação Coquali n. 42 de 25 de março de 2011. Divulga as Organizações Sociais qualificadas no âmbito da prefeitura e as respectivas áreas de atuação. Rio de Janeiro: PMRJ-Coquali, 2011 a.

. Deliberação Coquali n. 43 de 6 de abril de 2011. Dispõe sobre o parecer da Coquali quanto à solicitação de qualificação como Organização Social das entidades que menciona. Rio de Janeiro: PMRJ-Coquali, $2010 \mathrm{~b}$.

. Deliberação Coquali n. 47 de 6 de julho de 2011. Dispõe sobre o parecer da Coquali quanto à solicitação de qualificação como Organização Social das entidades que menciona. Rio de Janeiro: PMRJ-Coquali, 2011c.

- Deliberação Coquali n. 56 de 23 de dezembro de 2011. Dispõe sobre o parecer da Coquali quanto à solicitação de qualificação como Organização Social das entidades que menciona. Rio de Janeiro: PMRJ-Coquali, 2011d.

. Deliberação Coquali n. 60 de 7 de março de 2012. Dispõe sobre a obrigatoriedade de cumprimento da norma contida no art. 19 da Lei Municipal n. 5.026 de 19 de maio de 2009. Rio de Janeiro: PMRJ-Coquali, 2012a.

. Deliberação Coquali n. 61 de 27 de março de 2012. Dispõe sobre o parecer da Coquali quanto à solicitação de qualificação como Organi- 
zação Social das entidades que menciona. Rio de Janeiro: PMRJ-Coquali, $2012 b$.

. Deliberação Coquali n. 67 de 16 de maio de 2012. Dispõe sobre o parecer da Coquali quanto à solicitação de qualificação como Organização Social das entidades que menciona. Rio de Janeiro: PMRJ-Coquali, 2012c.

. Deliberação Coquali n. 74 de 15 de agosto de 2012. Dispõe sobre o parecer da Coquali quanto à solicitação de qualificação como Organização Social das entidades que menciona. Rio de Janeiro: PMRJ-Coquali, 2012d.

. Deliberação Coquali n. 85 de 25 de abril de 2013. Dispõe sobre o parecer da Coquali quanto à solicitação de qualificação como Organização Social das entidades que menciona. Rio de Janeiro: PMRJ-Coquali, $2013 \mathrm{a}$.

. Deliberação Coquali no 87 de 25 de julho de 2013. Dispõe sobre a instauração de processos de desqualificação e dá outras providências. Rio de Janeiro: PMRJ-Coquali, 2013b.

. Deliberação Coquali n. 96 de 31 de março de 2014. Dispõe sobre o parecer da Coquali quanto à solicitação de qualificação como Organização Social das entidades que menciona. Rio de Janeiro: PMRJ-Coquali, 2014a.

. Deliberação Coquali n. 97 de 17 de junho de 2015. Torna sem efeito a menção às entidades nas deliberações. Rio de Janeiro: PMRJ-Coquali, $2014 b$.

. Deliberação Coquali n. 103 de 25 de outubro de 2014. Dispõe sobre a instauração de processos de desqualificação e dá outras providências Rio de Janeiro: PMRJ-Coquali, 2014c.

GRANEMANN, S. Políticas sociais e financeirização das políticas de trabalho. Revista Em Pauta, Rio de Janeiro, n. 20, 2007.

MARTINS, A. S. A direita para o social. Juiz de Fora: Editora UFJF, 2009.

MARTINS, A. S. et al. Fundamentos teóricos da formação/atuação dos intelectuais da nova pedagogia da hegemonia. In: NEVES, L. M. W. (Org.). A direita para o social e esquerda para o capital: intelectuais da nova pedagogia da hegemonia no Brasil. São Paulo: Xamã, 2010.

MELO, M. P. Esporte e juventude pobre: a Vila Olímpica da Maré e as políticas públicas de lazer. Campinas: Autores Associados, 2005.

- Esporte e dominação burguesa no século XXI: a agenda dos Organismos Internacionais e sua incidência nas políticas de esportes no Brasil de hoje. Tese (Doutorado -Serviço Social). Universidade Federal do Rio de Janeiro, Rio de Janeiro, 2011. 
MELO, M. P. de; CUNHA, M; ANDRADE, G. Organizações Sociais e as políticas de esportes na cidade do Rio de Janeiro: dilemas e contradições no Programa Vilas Olímpicas. Rio de Janeiro: EEFD-UFRJ, 2014.

NEVES, L. M. W. (Org.). A direita para o social e a esquerda para o capital. São Paulo: Xamã, 2010.

NETTO, J. P. Capitalismo monopolista e Serviço Social. São Paulo: Cortez, 2005.

ONU. Força-Tarefa interagências da ONU. Esporte para o desenvolvimento e paz: em direção à realização das metas de desenvolvimento do milênio. Nova lorque: Nações Unidas, 2003.

RIO DE JANEIRO. Tribunal de Contas do Município. Relatório de Inspeção Ordinária (SMEL). Rio de Janeiro: PMRJ/TCM, 2004.

Câmara Municipal do Rio de Janeiro. Lei n. 5.026 de 19 de maio 2009. Dispõe sobre a qualificação de entidades como Organizações Sociais e dá outras providências. Rio de Janeiro: CMRJ, 2009a.

. Decretos n. 30780 de 2 de junho de 2009. Regulamenta a Lei Municipal n. 5026 de 19 de maio de 2009, que dispõe sobre a qualificação de entidades como organizações sociais [...]. Rio de Janeiro: PMRJ, $2009 \mathrm{~b}$.

. Secretaria Municipal de Esporte e Lazer. Resolução SMEL n. 603 de 7 de maio de 2012. Aprova na forma de anexo único desta resolução o regulamento da apresentação de pedido de qualificação como organizações sociais [...]. Rio de Janeiro: PMRJ/SMEL, 2012.

Secretaria Municipal da Casa Civil. Cartilha das Organizações Sociais cariocas: um brinde aos dois anos de vigência da Lei Municipal n. 5.026 de 19 de maio de 2009. Rio de Janeiro: PMRJ-SMCC, 2011.

Recebido em 05 de maio de 2015.

Aprovado para publicação em 06 de junho de 2016.

DOI: $10.12957 /$ rep.2016.27866

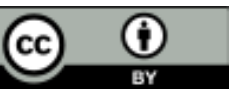

A Revista Em Pauta: Teoria Social e Realidade Contemporânea está licenciada com uma Licença Creative Commons Atribuição 4.0 Internacional. 